\title{
Tuberculous Meningitis in Children in Russia: Diagnostic Features and Clinical Observations
}

\author{
L.V.Klochkova*, M.E.Lozovskaya, E.B.Vasilyeva, Yu.A.Yarovaya \\ Saint Petersburg State Pediatric Medical University, Ministry of Health of the Russian Federation, Saint Petersburg, Russia
}

\section{Article Info}

\section{Article Notes}

Received: September 28, 2019

Accepted: December 05, 2019

\section{*Correspondence:}

Dr. Ludmilla V. Klochkova, St. Petersburg State

Pediatric Medical University, Litovskaya Ulitsa, 2, SanktPetersburg-194100, Russia; Telephone No: +7 904339 8133; Email: Iklochkova@yahoo.com

( 2019 Klochkova LV. This article is distributed under the terms of the Creative Commons Attribution 4.0 International License.

\section{Keywords}

Tuberculous meningitis

Children

Immunodiagnostics

Laboratory diagnostics

\section{Abstract}

Background: The study aimed to identify causes of delayed diagnosis and define features of tuberculous meningitis in children in the Russian Federation.

Materials and Methods: The study is based on data from 2000 to 2016 on frequency of meningitis in children in Russia. Further analysis of disease features and diagnostics of tuberculous meningitis in children in St. Petersburg over 12 years (2005-2016) is presented.

Results and Discussion: The number of cases of tuberculous meningitis in children in Russia decreased from 51 to 13 per year from 2000 to 2016. In St. Petersburg, from 2005 to 2016 there were 7 registered cases; 4 died, 3 survived. Predisposing factors of development of tuberculous meningitis were young age, presence of tuberculosis in the family, absence of BCG vaccination, and unfavorable social conditions. Three out of 7 children infected with HIV developed tuberculosis. However, a low frequency of cases has led to absence of phthisis vigilance, delayed diagnosis and deaths. Two illustrative cases are presented from clinical practice.

Conclusion: Improving outcomes of tuberculous meningitis requires enhanced phthisis vigilance, detection of mycobacterium tuberculosis infection by modern methods, use of all methods of etiological diagnostics, including PCR and Bactec, and immediate administration of antituberculous therapy.

\section{Introduction}

Tuberculous meningitis is a specific inflammation of brain meninges (pia matter and arachnoid) caused by mycobacterium tuberculosis. Children of age 0-14 years account for $0.4 \%$ meningitis cases among all cases of tuberculosis ${ }^{1}$. Involvement of nervous system is one of the most severe variants of primary tuberculosis infection and a principal cause of tuberculosis mortality in childhood $^{2,3,4}$. So, according to data from Kamaeva and Chugaev ${ }^{5}$, autopsies from $34 / 52$ (63\%) children who died from tuberculosis had a specific involvement of the meninges. A high level of disability is observed among those children who had tuberculous meningitis ${ }^{6,}$ 7. Children of early age are included in the high-risk group for tuberculous meningitis. Additionally, tuberculous meningitis in children aged under 3 years is still characterized by an extremely severe course and is often accompanied by the involvement of other organs and systems $(84.3 \%)^{8}$. In addition, aggravating factors include HIV infection, which complicates diagnosis and contributes to the severe course of tuberculous meningitis that could be fatal ${ }^{10}$. Notably, from the beginning of the 21st century, there has been a marked decrease of tuberculous meningitis cases from 51 to 13 in the Russian Federation ${ }^{9}$. 
Frequently, tuberculous meningitis is considered only after administration of long-term treatment with wide spectrum antibiotics due to suspected meningitis or meningoencephalitis of another etiology withouta desirable result ${ }^{11}$. Therefore, in case of the presence of meningitis of unclear etiology in a child, tuberculous meningitis should be included in diagnostics from the early days of the disease $\mathrm{e}^{12,13,14}$. Delayed diagnosis of tuberculous meningitis, and, consequently, untimely initiation of treatment (after 10 days of the disease), reduce the chance to recover and lead to death ${ }^{15}$. Recently new methods of diagnostics of latent tuberculous infection and local forms of tuberculosis of pulmonary and extrapulmonary localizations, have been introduced. A skin test with a recombinant tuberculous allergen has recently been developed by Russian scientists in 2008, - Diaskintest preparation which contains two antigenes of virulent Mycobacterium tuberculosis - ESAT6 and CFP-10, that are absent in Mycobacterium bovis $B C G$ vaccinal strain, and also in vitro tests using the same antigens: QuantiFERON-TBGold (QFT) "Cellestis" (Australia) and T-SPOT.TB "OxfordImmunotec" (Great Britain). Recently developed molecular-genetic methods of express diagnostics of mycobacterium tuberculosis based on polymerase chain reaction (PCR), accelerated culture method of mycobacterium tuberculosis detection in liquid nutrient media in automated complex Bactec are also of significance. Application of all these methods in tuberculous meningitis has previously been reported ${ }^{16,17 \text {, }}$ 18,19 .

\section{Research objective}

To analyze the causes of delayed diagnosis and features of tuberculous meningitis in children in present day Russia.

\section{Methods}

We studied the 17-year period data of official statistics on frequency of tuberculous meningitis in children within the territory of the Russian Federation (2000 - 2016), and frequency, features of the course and diagnostics of tuberculous meningitis in children of Saint Petersburg for the period of 12 years (2005 - 2016). Two illustrative clinical cases are also presented. The study was approved by the institutional ethics committee, and for the case reports, consent was obtained from the patients' next-ofkin.

\section{Results}

According to data from Shilova (2015) 9, the number of children with tuberculosis of brain covers in the Russian Federation was 13 patients in 2014, a decline from 51 in 2000. Data on the number of cases of tuberculous meningitis in children in the Russian Federation was obtained from the results of official statistics of the country (Figure 1).

In 2015-2016 the number of children with tuberculous meningitis was the same as $2014-13$ patients. However, these data are incomplete since some cases of tuberculosis of the central nervous system and meninges are registered as disseminated forms of tuberculosis 9 . Data on the number of cases of tuberculous meningitis in children in St. Petersburg was obtained from official registration with the epidemiological bureau of the city.

From 2005 to 2016, there were 7 cases of tuberculous meningitis in children in Saint Petersburg, 4 of whom died and 3 survived. Two children who died were migrants without registration in Saint Petersburg. Five of these 7 patients were children of early age (under 3 years of age), one patient was a preschool child of 4 years old and one of school age (13 years old). All patients had tuberculous meningitis as a manifestation of generalized tuberculosis, in 3 children it was combined with HIV-infection. The majority of patients ( 5 of 7 ) lived in unfavourable social conditions. Six of 7 children had a family tuberculous contact with a patient harboring the bacteria, but since this fact was determined after the child had acquired the disease, no preventive measures had been taken. BCG vaccination had not been administered in 5 of 7 children. Since 2009 to verify a tuberculous infection, including tuberculous meningitis, a tuberculous recombinant antigen Diaskintest has been used as a skin test, instead of the Mantoux test with $2 \mathrm{TE}$, or simultaneously. Three of 4 patients with tuberculous

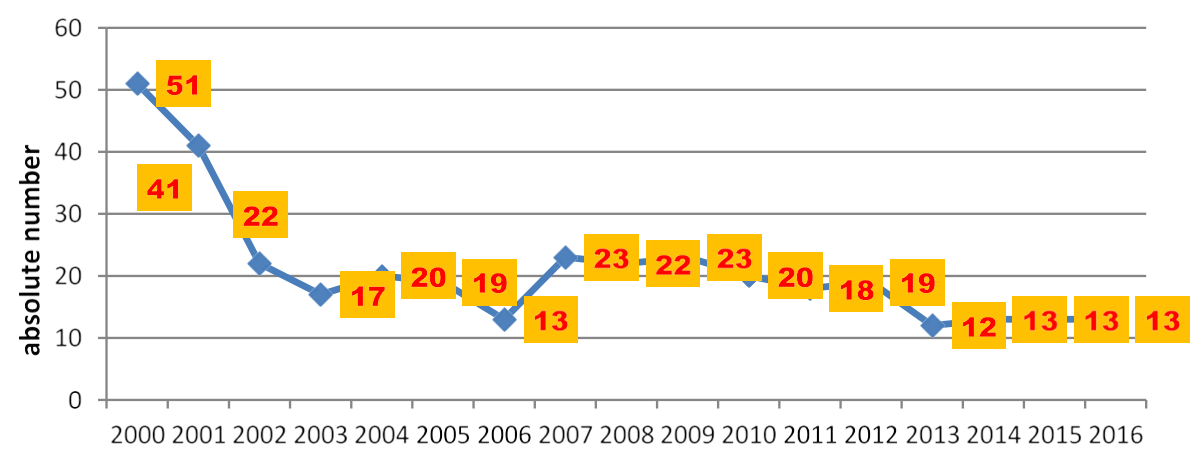

Figure 1: Time course of absolute numbers of children with tuberculous meningitis in Russia (data from ref 9 ) 
meningitis who received Mantoux test and Diaskintest had negative results and only 1 case was positive. This could be explained by the presence of anergy caused by a severe course of the tuberculous process, and/or the presence of HIV-infection. Another method of immunodiagnostics of tuberculosis QuantiFERON-TB Gold (QFT) - in vitro analogue of Diaskintest, demonstrated better sensitivity than Diaskintest in 2 cases of tuberculous meningitis. The result was positive with a negative Diaskintest and Mantoux test. Traditional methods of diagnosis with investigation of all available pathological material, especially cerebrospinal fluid still remain current (microscopy with Ziehl-Neelsen staining, luminescent microscopy including precipitation of fibrin, culture in liquid and dense nutrient media). Given the necessity of urgent diagnostics, the methods of express identification of mycobacterium tuberculosis have a clear advantage: PCR and Bactec (automated complex of mycobacterium tuberculosis cultivation on liquid media). Cerebrospinal fluid PCR allows confirming the diagnosis within 1-2 days. All 7 cases of tuberculous meningitis had bacteriological confirmation. Mycobacterium tuberculosis in 6 cases was sensitive to anti-TB drugs. Unfortunately, 4 cases of death took place in the setting of delayed diagnosis of tuberculous meningitis, and a possible tuberculous etiology of the disease ( 2 cases) was not even considered. In fact, 2 children were diagnosed by generalized tuberculosis complicated by tuberculous meningitis posthumously in city hospitals without an ante-mortem diagnosis of tuberculosis. Thus, untimely diagnosis (later than 2 weeks from the onset of the disease) was in 4 of 7 cases of tuberculous meningitis, which led to deaths of these children.

\section{Clinical case No. 1}

A 13-year old boy, with unstated tuberculosis contact and satisfactory social conditions, was inoculated by BCG vaccine in a maternity home and formed a scar of $5 \mathrm{~mm}$. The results of earlier Mantoux tests were doubtful (papule of $2-3 \mathrm{~mm}$ ), at the year of presentation the papule was 5 $\mathrm{mm}$. The disease onset was gradual, with repeated acute viral respiratory infections over 6 months. He showed signs of rheumatic syndrome, with a fever of $39^{\circ} \mathrm{C}$. The patient was hospitalized with the diagnosis "juvenile chronic arthritis or chronic tonsillitis". The hospital diagnosis was "recurrent streptococcal infection, acute myocarditis, arthritis, bacterial endocarditis". The chest roentgenogram showed thickened pleura with evidence of miliary dissemination (Figure 2).

After 1 month of hospitalization meningitis developed, the patient was examined for all possible infections except tuberculosis. After 1.5 months after hospitalization, there was an increase of brain symptomology, excitation with hallucinations, bradycardia, convulsions, cranial nerve symptoms, abduction of the left eye upward, differential

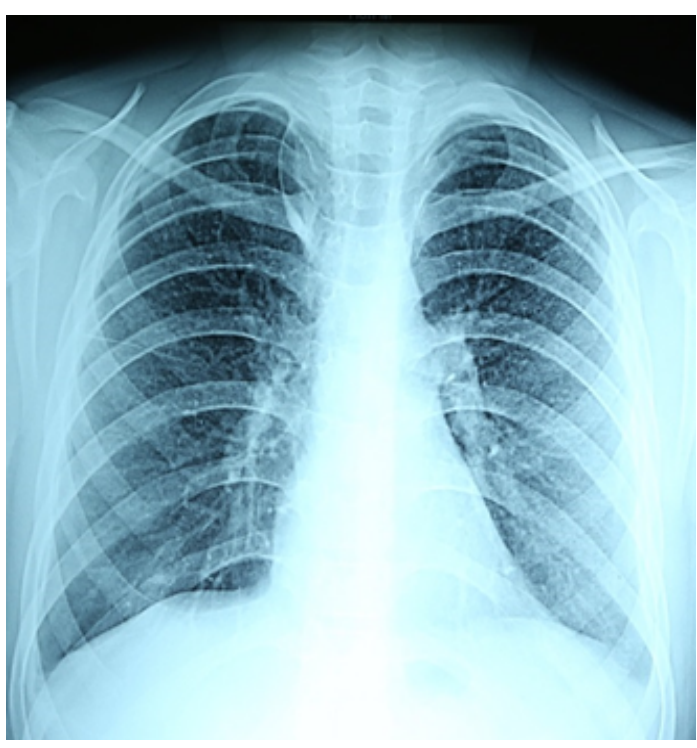

Figure 2: Roentgenogram of the lungs: small miliary foci in all pulmonary fields (clinical case No. 1).

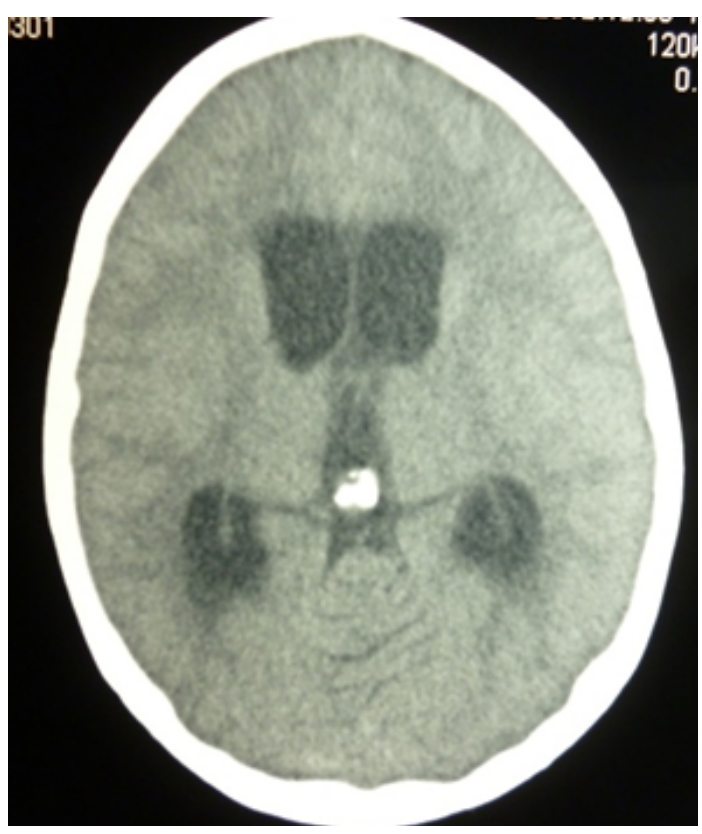

Figure 3: Computer tomogram of the brain: hydrocephaly (clinical case No. 1).

width of palpebral fissures. The computer tomography of the brain revealed hydrocephaly (Figure 3).

After 2 months of hospitalization, the patientslipped into coma stage III; death ensued. A consult with a TB specialist was obtained one day before death. Cerebrospinal fluid test indicated the following: 1. (2 1/2 weeks before death): proteins $-0.5 \mathrm{~g} / \mathrm{l}$; cell count - 11 cells per $1 \mathrm{mcl}$, neutrophils - 79\%, lymphocytes - 21\%, culture for sterility - microflora was not identified. 2 . (4 days before death): cell count - 21 cells per $1 \mathrm{mcl}$ with the prevalence of lymphocytes, proteins - $3.0 \mathrm{~g} / \mathrm{l}$, chlorides - $85.0 \mathrm{mmol} / \mathrm{l}$ (decreased), glucose - 


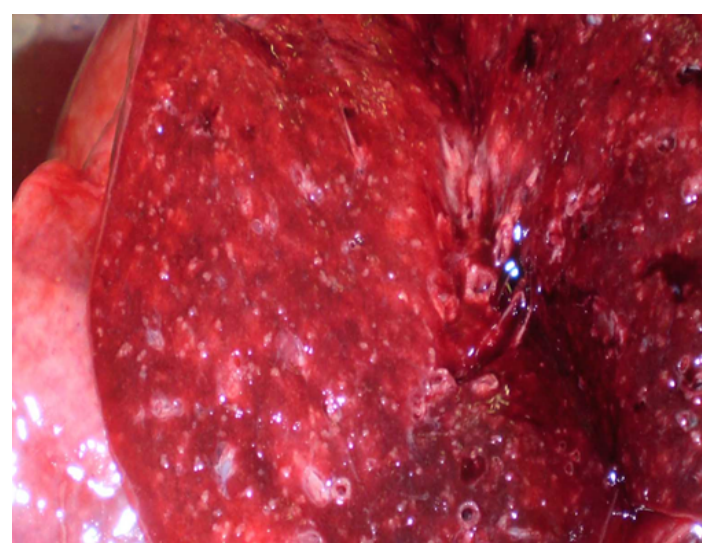

Figure 4: Macropreparation of lung tissue - miliary foci (clinical case No. 1).

$0.22 \mathrm{mmol} / \mathrm{l}$ (decreased), microflora were not cultured. The pathologic diagnosis was as follows: primary tuberculosis of the lungs, subacute course, in a progressive stage, with lymphatic dissemination: multiple miliary tubercles in the lungs (Figure 4); lymph nodes (paratracheal, peribronchial, of liver hilum); palatine tonsils; liver; kidneys; pleura tuberculosis (with adhesion); brain (leptomeningitis; ependymitis, chorioiditis), with focal necrosis of the cortex, development of progressive hydrocephaly. The diagnosis was made posthumously and confirmed by histological investigation, detection of Mycobacterium tuberculosis by PCR method and bacteriological culture in lung tissue and by immunohistochemical investigation. Mycobacterium tuberculosis was sensitive to all drugs.

\section{Clinical case No. 2}

A boy of 4 years and 8 months, a visitor from Novokuznetsk, had family contact with his father who was suffering from HIV-infection and died due to bilateral infiltrative tuberculosis (mycobacterium tuberculosis +), when the child was 4 months old. Because of this, the child received a course of chemoprophylaxis during the first year of life and once more - at 2 years. Repeated contact occurred at 4 years and 8 months with a friend of his stepfather who had generalized tuberculosis, tuberculous meningitis. The child was not immunized by BCG vaccine (his mother had HIV-infection). He was admitted in the second week of the disease. His condition was severe, with flaccidity, and horizontal nystagmus in extreme abduction. A bilateral Babinski response was detected, with hyperesthesia, acute positive meningeal symptoms. Chest CT scan identified calcifications of intrathoracic lymph nodes and pulmonary tissue (Figure 5). Mantoux test 2 TE showed papula of $12 \mathrm{~mm}$, Diaskintest papula - of $17 \mathrm{~mm}$, QuantiFERON-TB - of 8.679 IU/ml (positive). Cerebrospinal fluid showed cytosis 1296/3 (1096 - mononuclear cells, 200 neutrophils), protein - $2.64 \mathrm{~g} / \mathrm{l}$, chlorides - $93 \mathrm{mmol} / \mathrm{l}$, sugar - $0.7 \mathrm{mmol} / \mathrm{l}$ (in blood - $4.4 \mathrm{mmol} / \mathrm{l}$ ). Cerebrospinal

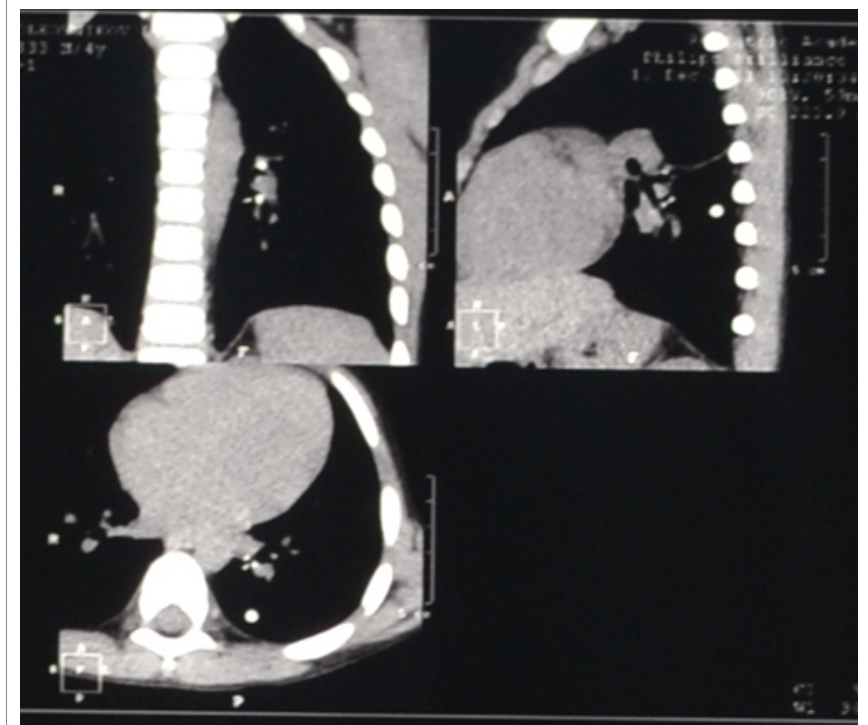

Figure 5: Chest Computer Tomography-calcification in intrathoracic lymph nodes and lung tissue (clinical case No. 2).

fluid investigation for mycobacterium tuberculosis by PCR method was negative, as well as by Bactec method. M. tuberculosis was identified in a cerebrospinal fluid film by the method of direct microscopy with Ziehl Neelsen staining and bacteriological culture on solid medium. Mycobacterium tuberculosis was sensitive to all drugs. A diagnosis of primary generalized tuberculosis was made: tuberculous meningitis (basilar form), mycobacterium tuberculosis $(+)$, tuberculosis of intrathoracic lymph nodes of tracheal bifurcation and bronchopulmonary groups with calcification, mycobacterium tuberculosis negative. Treatment started on the 8th day of the disease onset led to full recovery.

\section{Discussion}

At admission to hospital with meningeal syndrome, as well as with any other pathology suspicious for tuberculosis, the patient should receive the minimum required clinical examination for tuberculosis: clinical blood analysis, general urine analysis, chest roentgenogram, Mantoux test 2TE, culture of sputum or bronchial wash for mycobacterium tuberculosis. Contacts of patients with tuberculosis should be identified. One of the reasons for the late diagnosis in St. Petersburg is the lack of registration of migrants ( 2 cases), and therefore, children were not observed by pediatricians early enough and considered to belong to group of high risk. Pediatricians did not know that children's parents had tuberculosis. In addition to these two children, another 4 had contact with relatives with tuberculosis, but this became known only after the illness of the children was discovered. They lived in very poor conditions. Parents paid little attention to children's health. It is also important to know the Mantoux tests 2 TE results. A skin test with tuberculous recombinant allergen 
(CFP10-ESAT6 protein, $0.2 \mathrm{mkg}$ ) - Diaskintest preparation is an obligatory component of tuberculosis diagnostics of any localization in modern conditions in Russia ${ }^{20}$. However, negative results of Diaskintest and Mantoux test with 2TE do not rule out tuberculous etiology, because of secondary anergy characteristic for generalized tuberculosis, and presence of accompanying HIV-infection. This confirmed our observations of 3 patients with tuberculous meningitis combined with HIV infection.

Another reason for the late diagnosis is related to the lack of alertness of pediatricians due to the rarity of tuberculous meningitis. In most cases, another etiology of meningitis was suspected. The search for Mycobacterium tuberculosis in cerebrospinal fluid and other materials, clinical and radiological studies for tuberculosis were not carried out in a timely manner. Tuberculosis in children often proceeds under the guise of other diseases. Thus, in the first case described, a child of 2 months was in a hospital with a diagnosis of rheumatoid arthritis, myocarditis. Therefore, along with cutaneous tests, it is reasonable to use in vitro diagnostic tests, based on interferon- $\gamma($ IFN $-\gamma$ ) release by blood T-lymphocytes in response to stimulation with ESAT-6 and CFP-10 antigens. Two such tests Quanti FERON-TB Gold (Cellestis, Australia) test and T-SPOT.TB (OxfordImmunotec, Great Britain) are currently used in the Russian Federation for immunodiagnostics of tuberculosis.

Screening roentgenogram of the chest, computed tomography (CT) of the chest abdomen, and head will help to determine tuberculosis changes in different organs (infiltrates, foci, calcifications). Consultations with a neurologist, ophthalmologist (examination of eye grounds), TB specialists can also be helpful. If the diagnosis of tuberculous meningitis is made, specific therapy including 4 antituberculosis preparations is immediately administered. Pending results, it is recommended to administer test-therapy of 3 antitubercular drugs.

Thus, to improve the outcomes of tuberculous meningitis it is necessary to increase phthisis vigilance among doctors in the institutions of the general medical network, especially in children at risk, as well as to be able to establish mycobacterium tuberculosis infection by such modern methods as Diaskintest, QuantiFERON-TB Gold, T-SPOT.TB, to search for contacts with tuberculosis by $\mathrm{X}$-ray examination of the environmental contacts, to use all methods of etiological diagnostics, including express methods of PCR and Bactec, solid media bacteriological culture, in both cerebrospinal fluid and other materials. It is obligatory to include tuberculosis in differential diagnosis of meningitis, and to administer antitubercular drugs immediately in case of suspicion of tuberculous meningitis, without waiting for the definitive results of the investigation.

\section{References}

1. Tuberculosis in the Russian Federation 2012/2013/2014. Moscow Russia. 2015; 312 p.

2. Yanchenko EN, Greymer MS. Tuberculosis in children and teenagers: management for doctors. Saint-Petersburg Russia Hippocrates. 1999; $336 \mathrm{p}$.

3. Kobeleva YaM, Greenberg LM, Chugayev YuP, et al. Lethal cases of tuberculosis in children: clinico-epidemiological data. Ural'skij medicinskij zhurnal. 2011; 1: 72-76.

4. Chugayev YuP, Greenberg LM. The clinical and morphological characteristic of lethal cases in infants with primary tuberculosis. Sverdlovsk Russia Materialy Sverdlovskogo filiala NPO Ftiziopul'monologija. 1991; 96-100.

5. Kamayeva NG, Chugayev YuP. The experience of revealing and diagnostics of tubercular meningitis in children. Medicinskij aljans. 2014; $2: 32-38$

6. Bang ND, Caws M, Bang ND, et al. Clinical presentation, diagnosis, mortality and prognostic markers of tuberculosis meningitis in Vietnamese children: a prospective descriptive study. BMC Infect Dis. 2016 Oct 18; 16 (1): 573.

7. Dhawan SR, Gupta A, Singhi N, et al. Predictors of Neurological Outcome of Tuberculous Meningitis in Childhood: A Prospective Cohort Study From a Developing Country. J Child Neurol. 2016 Dec; 31(14): 1622-1627.

8. Sevostyanova TA, Klimov GV, Shirshov IV, et al. Tubercular meningitis in infants. Tuberkulez i social'no znachimye zabolevanija. 2014; 5: 32-39.

9. Shilova MV. Tuberculosis in Russia in 2014. Monograph.Moscow Russia Pero. 2015; 240 p.

10. Skripchenko NV, Ivanova MV, Vilnits AA, et al. Neuroinfections at children tendencies and prospects. Rossijskij vestnik perinatologii i pediatrii. 2016; 4: 9-22.

11. Sorokina MN, Ivanova VV. Bacterial meningitis in children. Moscow Russia Medicine. 2003; 320 p.

12. Skripchenko NV. Cerebrospinal fluid and prospects of its studying Rossijskij vestnik perinatologii i pediatrii. 2011; 6: 88-97.

13. Vilnits AA, Ivanova MV, Skripchenko NV, et al. Kliniko-epidemiological aspects of a generalized meningococcal infection in children and teenagers of St. Petersburg Pediatr. 2017; 8: 84.

14. Klochkova LV, Lozovskaya ME. Actual issues of modern diagnosis of tubercular meningitis in children at the present stage. Materials of V Baltic congress on children's neurology. Saint-Petersburg. 2015; p.192-193.

15. Korol OI, Lozovskaya ME. Tuberculosis in children and teenagers. Saint-Petersburg Russia Piter. 2005; 432 p.

16. Harchenko GA, Kimirilova OG, Chabanova ON. Tubercular meningitis in children and teenagers. Tuberkulez i bolezni legkih. 2017; 1: 47-50.

17. Lozovskaya ME, Belushkov VV, Gurina OP, et al. Comparative evaluation of innovative diagnostic tests for latent and active TB infection in children. Pediatr. 2014; 3: 46-50.

18. Rumzan A, Navil K, Asimi R. et al. Childhood tubercular meningitis: an institutional experience and analysis of predictors of outcome. Pediatr Neurol. 2013 Jan; 48(1): 30-5.

19. Vita S, Caraffa CE, Mascia MC. et al. Immunological diagnosis as an adjunctive tool for an early diagnosis of tuberculous meningitis of an immune competent child in a low tuberculosis endemic country: a case report. BMC Res Notes. 2017 Mar 13; 10(1): 123.

20. Federal clinical recommendations about diagnostics and treatment of a latent tuberculosis infection in children. Moscow Russia ROOI Zdorov'e cheloveka. 2015; 36 p. 